\title{
Voice Characteristics in Smith-Magenis Syndrome: An Acoustic Study of Laryngeal Biomechanics
}

\author{
Irene Hidalgo-De la Guía ${ }^{1, *}$, Elena Garayzábal-Heinze ${ }^{2}$ ad and Pedro Gómez-Vilda ${ }^{3}[$ \\ 1 Centro de Educación Superior CUNIMAD, Universidad de Alcalá de Henares, 28040 Madrid, Spain \\ 2 Linguistics Department, Universidad Autónoma de Madrid, 28049 Madrid, Spain; elena.garayzabal@uam.es \\ 3 Department of Architecture and Technology of Computer Systems, Universidad Politécnica de Madrid, \\ 28040 Madrid, Spain; pedro@fi.upm.es \\ * Correspondence: irene.hidalgo@cunimad.com
}

Received: 30 April 2020; Accepted: 25 August 2020; Published: 31 August 2020

\begin{abstract}
Smith-Magenis syndrome (SMS) is a rare genetic disease characterized by intellectual disability, serious behavior disorders, neurodevelopment delay, and speech and language disorders. An acoustic and biomechanical analysis of the voice of SMS young adults was carried out due to (a) the close relationship between the laryngeal biomechanics and the clinical and emotional state of a person; (b) the fact that no research on the voice in this syndrome has been conducted previously. The vocal timbre of most people diagnosed with SMS does not seem to be according to the complexion of diagnosed individuals, nor to their gender and age, so it could be interesting to attend the analysis of phonation of people with a rare genetic syndrome such as SMS. We used BioMetPhon, a specific piece of software to analyze the glottal source and biomechanics of vocals folds. Nineteen features related to dysphonia, physiology, and biomechanics of the vocal folds were considered. The adult phonation of 9 individuals with SMS was analyzed and compared to 100 normative male and female adult voices. Results showed that the phonation of the SMS group significantly deviates from the adult normophonic profile in more than one of the 19 features examined, such as stiffness of the thyroarytenoid muscle and dynamic mass of the vocal fold cover, among others.
\end{abstract}

Keywords: Smith-Magenis syndrome; voice; laryngeal biomechanics; vocal folds; behavior disorders; dysphonia

\section{Introduction}

Smith-Magenis syndrome (SMS) is a genetic disorder considered a rare disease that affects 1 to 15/25,000 births, regardless of gender, ethnicity, and social status (Elsea and Girirajan 2008). It was first described in 1982 (Smith et al. 1982) and the most frequent cause-identified in 70\% of the patients with SMS-is an interstitial microdeletion in the p11.2 region of chromosome 17. A mutation of the RAI 1 gene has also been found in this same region in those cases that do not present such microdeletion (Elsea and Girirajan 2008). The fluorescent in situ hybridization system (FISH) or the microarray comparative genomic hybridization (aCGH) are two different techniques to detect the syndrome.

In general terms, the genetic abnormality that causes this syndrome results in a series of neurodevelopmental disorders and clinical, physical, neurocognitive, and behavioral alterations typical of Smith-Magenis syndrome. The neurological profile of SMS results from abnormal development of the nervous system in the embryonic stage. Individuals with this syndrome present cranioencephalic alterations, developmental delay, hypotonia, hyporeflexia, maturation delay, high pain threshold, and hyperacusis, among others (Greenberg et al. 1996; Gropman et al. 1998; Udwin et al. 2001; Webber 1999; Wolters et al. 2009). Neurodevelopmental disorders are related to a specific cognitive profile, which is characterized by moderate intellectual disability (IQ 42-60), poor working memory, 
and attention deficit and hyperactivity. Language is delayed and speech disorders continue into adulthood (Udwin et al. 2001; Solomon et al. 2002; Gropman et al. 2006; Garayzábal Heinze et al. 2011; Osório et al. 2012; Heinze and Lens 2013; Garayzábal et al. 2014; Hidalgo and Garayzábal 2019). Concerning the behavioral phenotype, individuals with SMS tend to easily show states of anxiety and nervousness, especially in new situations. They also present disruptive behaviors, hyperactivity, and sleep disorders due to the alteration of the circadian rhythm (Dykens et al. 1997; Dykens and Smith 1998; Sarimski 2004; Martin et al. 2006; Wilde et al. 2013; Shayota and Elsea 2019; Smith et al. 2019; Agar et al. 2020). A recent study found that behavioral problems seem to diminish over the years, although this is a conclusion based on subjective interpretations provided by the parents of 28 people with the syndrome (Nag and Nærland 2020). The most characteristic physical features are short stature, obesity, prognathism, curved upper lip, midface hypoplasia, and deep, hoarse voice (Elsea and Girirajan 2008; Heinze and Lens 2013).

The last feature related to the voice is striking, as it is a very remarkable characteristic in this syndrome. Some studies highlight the hoarse and deep voice of these patients (Gropman et al. 1998, 2006; Udwin et al. 2001; Di Cicco et al. 2001; Solomon et al. 2002; Elsea and Girirajan 2008; Heinze and Lens 2013; Smith et al. 2019), but no further details or analysis have been offered on this statement. Additionally, there are no studies that refer specifically to the analysis of voice acoustic parameters in SMS. From our experience working with people with SMS, their voices do not seem to be in line with their age, sex, or complexion. For example, there are cases of 8-year-old girls with extremely low vocal tones and cases of tall teenage boys with very high voices. In addition to this striking feature, many individuals have a hoarse vocal timbre that sounds strained and seem to show excessive tension in all their voice emissions. The latter could be related to the anxious and tense character of SMS individuals (Dykens and Smith 1998; Sarimski 2004; Elsea and Girirajan 2008; Smith et al. 2019). However, these descriptions are subjective since they are based on observation, and objective studies are needed. As far as we know, currently, there is only an introductory work on the voice of children and adults with SMS in which the anxious nature of the SMS individuals is pointed out as a possible cause of the particular voice timbre observed (Hidalgo de la Guía 2019).

In this paper, which consists of an approximative study, we intend to examine SMS adult phonation (after voice change) to explore the phonation characteristics of the SMS population. Therefore, in this work, we analyzed the adult phonation of an adult group of individuals with SMS from an acoustic and biomechanical perspective. In this study, we are interested in observing the acoustic qualities of the SMS phonation and the laryngeal biomechanics underlying this voice timbre far from the profiles of normality. The condition of vocal folds and how they work in the SMS population might be conditioned by the clinical, physical, and behavioral features of this syndrome, since the laryngeal biomechanics are highly susceptible to all kinds of physiological conditions such as the emotional, physical, and, above all, clinical state of the speaker (Harel et al. 2004; Yunusova et al. 2008; Chenausky et al. 2011; Tsanas 2012; Gómez et al. 2013a, 2016, 2017). Furthermore, previous research on phonation in children with Down syndrome and Williams syndrome found features in their laryngeal biomechanics that could be related to neurological disorders in the former (Hidalgo et al. forthcoming) and to developmental delay and elastin deficit in the latter (Hidalgo et al. 2018).

Since the phonation of SMS individuals has been little analyzed (despite the fact that it is a striking feature that this population has in common), and because clinical and emotional features of the speakers are reflected in the laryngeal biomechanics, it seemed appropriate to carry out an exploratory study of adult phonation with SMS from an acoustic and biomechanical perspective. The aim of this study, hence, is to describe the phonatory profile of the adult voice in this syndrome and to observe whether there are characteristics in their voices different from the normative population. 


\section{Materials and Methods}

\subsection{Materials for Phonation Analysis}

To carry out the analysis of phonation, a software developed for application in the clinical field has been used: BioMetPhon. It is part of a package of programs for the analysis of the glottic wave, Glottex Voice Analysis System, developed by the Universidad Politécnica de Madrid (Gómez et al. 2009, 2013a).

BioMetPhon performs the analysis of a 500-millisecond vowel fragment extracted from a voice recording, normally consisting of an open vowel, usually /a/. The methods used by the tool are based on inverse filtering and modeling. A comprehensive description of the procedures used can be found in Gómez et al. (2009).

The tool makes a reverse reconstruction of the filter (the vocal tract) to remove it and to examine only the glottic source (the product of the vocal folds) by analyzing the source and flow during a glottic cycle (Liljencrants-Fant pattern, Fant et al. 1985), which begins with the complete closure of the folds. BioMetPhon takes different biometric data extracted in each glottic cycle for the analysis: the maximum closing instant of the vocal folds, two points of recovery of this closing (tR1 and tR2), two instants of opening (tO1 and tO2), and a maximum opening instant (tM) (Gómez et al. 2009, 2011, 2013a, 2013b).

The software version used (version 5.0, from February 2018) estimates 72 acoustic and biomechanical features to carry out the analysis from a $500 \mathrm{~ms}$ sample of a sustained vowel. These 72 features are shown in Table 1.

Table 1. Set of 72 features estimated by the tool regarding its characteristics and purpose.

\begin{tabular}{cc}
\hline Feature Number & Description \\
\hline 1. & Pitch \\
2. & Jitter \\
3. & Shimmer \\
5. & Noise-harmonics ratio \\
6 & Energy average \\
$7-20$ & 14 features: cepstral description of the glottal source \\
$21-34$ & 14 features: related with maxima and minima of glottal source power spectral density \\
$35-46$ & 12 features: biomechanical descriptor of the vocal folds (body and cover) \\
$47-58$ & 12 features: temporal descriptors of the glottal source (contact and open phase) \\
$59-62$ & 4 features: glottal gap (flow, recovery, contact, and adduction) \\
$63-65$ & 3 features: indicators of neurological alteration \\
$66-72$ & 7 features: estimation of tremor \\
\hline
\end{tabular}

Since this study aims to explore the adult phonation of those with SMS and, in particular, to observe whether there are characteristics in their voices different from the normative population, 19 features have been selected from the 72 indicated in Table 1 . These particular features are used to estimate the acoustic and biomechanical properties of vocal folds, thus achieving the main interest of this study, and are related to acoustic distortion: jitter, shimmer, harmonic to noise ratio, etc. (features 1-5); biomechanical features (35-46), which account for the functioning and state of the vocal folds: body mass, cover mass, body stiffness, cover stiffness, etc.; features referring to the closure and contact of the vocal folds: adduction gap, contact gap, permanent gap (59-62); and features related to laryngeal tremor (66-72). The 19 acoustic and biomechanical features are identified in Table 2. 
Table 2. List of the 19 acoustic and biomechanical features used in this study.

\begin{tabular}{ll}
\hline Feature & Description \\
\hline 1. Fundamental frequency (F0) & Fundamental phonation frequency \\
2. Jitter & Normalized difference in F0 between neighbor phonation cycles \\
3. Shimmer & Normalized difference in average amplitude between neighbor phonation cycles \\
5. Noise-Harmonic Ratio & Ratio between turbulent and harmonic spectral components \\
35. Body Dynamic Mass & Amount of body mass contributing to oscillation \\
37. Body Stiffness & Transversal dynamic tension on the vocal fold body \\
38. Body Mass Unbalance & Relative change in feature 35 between neighbor phonation cycles \\
40. Body Stiffness Unbalance & Relative change in feature 37 between neighbor phonation cycles \\
41. Cover Dynamic Mass & Amount of cover mass contributing to oscillation \\
43. Cover Stiffness & Transversal dynamic tension on the vocal fold cover \\
44. Cover Mass Unbalance & Normalized difference in feature 41 between neighbor phonation cycles \\
46. Cover Stiffness Unbalance & Normalized difference in feature 43 between neighbor phonation cycles \\
60. Contact defect & Percent of airflow escape during the closed phase \\
61. Adduction defect & Percent of glottal gap seen altered during adduction \\
62. Permanent gap & Percent of glottal gap seen during the recovery phase \\
67. Physiological Tremor & Amplitude of the vocal fold stiffness low-frequency component \\
69. Neuromotor Tremor & Amplitude of the vocal fold stiffness mid-frequency component \\
71. Flutter Tremor & Amplitude of the vocal fold stiffness high-frequency component \\
72. Global Tremor & Root Mean Square Amplitude of the vocal fold stiffness tremor \\
\hline
\end{tabular}

The information offered by the BioMetPhon program, which consists of indirect estimates about vocal fold properties, makes it a useful tool in studies such as the one carried out here. Furthermore, it is important to remember that the methodology used in this study has been shown to be effective in previous research with populations with neurological alterations (Gómez et al. 2016, 2017; Hidalgo et al. 2018 and Hidalgo et al. forthcoming).

\subsection{Participants}

The study was conducted with 9 adolescents and adults (males $=6$; females $=3$ ) diagnosed with SMS between the ages of 16 and 33. Those cases aged 16 and 17 have been included because at this age, the voice has already changed and phonation matches the adult voice profile (Hollien et al. 1994; Harries et al. 1997; Whiteside 2001; Whiteside et al. 2004). All of them are members of the Smith-Magenis Association Spain (ASME) and obtained their diagnosis through the cytogenetic technique FISH (Fluorescence in situ hybridization). Table 3 shows the characteristics of each SMS case:

Table 3. Sex, age, height, weight and voice type of each participant with Smith-Magenis syndrome (SMS).

\begin{tabular}{cccccc}
\hline Participants & Sex & Age (Years/Months) & Height $(\mathbf{m})$ & Weight $(\mathbf{K g})$ & Voice Type \\
\hline SMS-14 & male & $16 ; 00$ & 1.56 & 54 & 1 \\
SMS-15 & female & $16 ; 01$ & 1.55 & 50 & 1 \\
SMS-16 & female & $17 ; 01$ & 1.48 & 34 & 1 \\
SMS-17 & male & $17 ; 04$ & 1.80 & 75 & 1 \\
SMS-18 & male & $18 ; 06$ & 1.62 & 55 & 1 \\
SMS-19 & female & $18 ; 09$ & 1.66 & 77 & 1 \\
SMS-20 & male & $21 ; 02$ & 1.55 & 55 & 1 \\
SMS-21 & male & $22 ; 06$ & 1.73 & 86 & 1 \\
SMS-22 & male & $33 ; 04$ & 1.72 & 73 & 1 \\
\hline
\end{tabular}

As a normophonic reference sample, the values incorporated in the BioMetPhon database of 100 adult male and female voices have been taken. It is a database of normative speakers thus confirmed after a complete evaluation by otorhinolaryngology specialists. The male dataset included normophonic participants between 21 and 62 years (mean $=42.3$, standard deviation $=11.2$ ). The female dataset included normophonic participants between 20 and 59 years $($ mean $=37.3$, standard deviation $=11.7$ ). This database provides the profile of normal adult phonation. 
Informed consent was obtained from the members responsible for the SMS participants by signing a document informing about the evaluation procedure and the purpose of the study.

\subsection{Collection of Voice Samples}

All recordings have been made with a lapel microphone (Audio-Technica ATR-3350), at 44,000 Hz and 16 bits, and with a Lenovo laptop (OS Windows 10, Realtek High Definition Audio). The microphone was placed 15-20 cm from the radiation source; thus, the lateral signals were very attenuated. All recordings have been made in a soundproof room at the State Reference Center for Rare Diseases (CREER) and individually. Only the principal investigator and the participant with SMS were in the room.

The voice samples collected consisted of a vowel/a/ held for one second. The reason this sound has been collected is its low and open character, from an articulatory point of view. These characteristics make it an affordable sound even for those with articulatory difficulties, such as people with SMS.

Special care was taken to ensure that the participant did not imitate the examiner's articulation and intonation. At least five voice samples were collected from each participant to obtain a more accurate response to the phonatory variability of the speaker.

The voice recordings were stored in the program database and were completely anonymous. The analysis software assigned each voice sample with a numerical code, which is related to the exact date and time at which the recording was obtained.

\section{Results}

The following are BioMetPhon's estimates after the analysis of the phonation of the nine participants with SMS. The value shown in Table 4 corresponds to the average of the five emissions made by each case with SMS:

The Kolmogorov-Smirnov test (KS test) was used for statistical data analysis to check which of the SMS phonations in this study deviate significantly from the profile of normality and on which features of the 19 analyzed a deviation was observed.

The results of the KS test are shown in the greyscale in Table 5. Black indicates statistically significant results that are above the normative average and light grey indicates statistically significant results that are below the normality profile. Those statistically significant reject the null hypothesis $(<0.05)$ :

Table 4. Average of the 5 voices of the 9 participants.

\begin{tabular}{|c|c|c|c|c|c|c|c|c|c|c|}
\hline & & SMS14 & SMS15 & SMS16 & SMS17 & SMS18 & SMS19 & SMS20 & SMS21 & SMS22 \\
\hline $\mathrm{N}$ & & 5 & 5 & 5 & 5 & 5 & 5 & 5 & 5 & 5 \\
\hline 1. Absolute Pitch (Hz) & Mean & 275 & 114 & 294 & 162 & 154 & 195 & 164 & 175 & 160 \\
\hline \multirow{2}{*}{ 2. Jitter (rel.) } & Mean & 0.0113 & 0.0510 & 0.0070 & 0.0062 & 0.0045 & 0.0122 & 0.0051 & 0.0045 & 0.0156 \\
\hline & St. Desv. & 0.0059 & 0.0480 & 0.0027 & 0.0017 & 0.0016 & 0.0088 & 0.0009 & 0.0008 & 0.0075 \\
\hline 3. Shimmer (rel.) & St. Desv. & 0.0040 & 0.0192 & 0.0018 & 0.0063 & 0.0025 & 0.0132 & 0.0031 & 0.0011 & 0.0018 \\
\hline \multirow{2}{*}{ 5. NHR (rel.) } & Mean & 0.7053 & 0.6368 & 0.7038 & 0.5883 & 0.5919 & 0.5757 & 0.6378 & 0.5580 & 0.5635 \\
\hline & St. Desv. & 0.1083 & 0.0326 & 0.0589 & 0.0440 & 0.0615 & 0.0207 & 0.0375 & 0.0239 & 0.0520 \\
\hline 35. Body Mass (mg) & Mean & 0.0090 & 0.0299 & 0.0083 & 0.0153 & 0.0160 & 0.0138 & 0.0151 & 0.0140 & 0.0156 \\
\hline \multirow{2}{*}{$\begin{array}{l}\text { 38. Body Mass } \\
\text { Unbalance (rel.) }\end{array}$} & Mean & 0.0039 & 0.2231 & 0.0033 & 0.0022 & 0.0012 & 0.0232 & 0.0018 & 0.0016 & 0.0092 \\
\hline & St. Desv. & 0.0018 & 0.3190 & 0.0025 & 0.0012 & 0.0006 & 0.0430 & 0.0007 & 0.0009 & 0.0095 \\
\hline
\end{tabular}


Table 4. Cont.

\begin{tabular}{|c|c|c|c|c|c|c|c|c|c|c|}
\hline & & SMS14 & SMS15 & SMS16 & SMS17 & SMS18 & SMS19 & SMS20 & SMS21 & SMS22 \\
\hline \multirow{2}{*}{$\begin{array}{l}\text { 40. Body Stiffness } \\
\text { Unbalance (rel.) }\end{array}$} & Mean & 0.0229 & 0.3055 & 0.0107 & 0.0118 & 0.0079 & 0.0458 & 0.0092 & 0.0076 & 0.0405 \\
\hline & St. Desv. & 0.0139 & 0.3753 & 0.0045 & 0.0038 & 0.0032 & 0.0626 & 0.0024 & 0.0010 & 0.0258 \\
\hline \multirow{2}{*}{ 41. Cover Mass (mg) } & Mean & 0.0066 & 0.0099 & 0.0075 & 0.0054 & 0.0062 & 0.0055 & 0.0093 & 0.0071 & 0.0052 \\
\hline & St. Desv. & 0.0015 & 0.0044 & 0.0039 & 0.0007 & 0.0002 & 0.0005 & 0.0015 & 0.0003 & 0.0018 \\
\hline \multirow{2}{*}{ 43. Cover Stiffness (mN/m) } & Mean & 20,251 & 10,355 & 25,536 & 8398 & 7832 & 13,011 & 11,025 & 9784 & 11,202 \\
\hline & St. Desv. & 3734 & 10,644 & 5936 & 929 & 289 & 2563 & 1941 & 523 & 6091 \\
\hline \multirow{2}{*}{$\begin{array}{l}\text { 44. Cover Mass } \\
\text { Unbalance (rel.) }\end{array}$} & Mean & 0.0526 & 0.1818 & 0.0284 & 0.0250 & 0.0173 & 0.0775 & 0.0312 & 0.0238 & 0.1393 \\
\hline & St. Desv. & 0.0104 & 0.2186 & 0.0044 & 0.0094 & 0.0021 & 0.0799 & 0.0093 & 0.0026 & 0.1673 \\
\hline \multirow{2}{*}{$\begin{array}{l}\text { 46. Cover Stiffness } \\
\text { Unbalance (rel.) }\end{array}$} & Mean & 0.0598 & 0.2638 & 0.0329 & 0.0263 & 0.0139 & 0.0975 & 0.0269 & 0.0222 & 0.1488 \\
\hline & St. Desv. & 0.0155 & 0.3245 & 0.0039 & 0.0135 & 0.0027 & 0.1070 & 0.0049 & 0.0029 & 0.1931 \\
\hline \multirow{2}{*}{ 60. Contact GAP (rel.) } & Mean & 0.0984 & 0.2170 & 0.0827 & 0.2749 & 0.1486 & 0.1492 & 0.1919 & 0.1079 & 0.3002 \\
\hline & St. Desv. & 0.0463 & 0.1581 & 0.0666 & 0.0703 & 0.0320 & 0.0520 & 0.0918 & 0.0123 & 0.0468 \\
\hline \multirow{2}{*}{ 61. Adduction GAP (rel.) } & Mean & 0.0225 & 0.1632 & 0.0100 & 0.0215 & 0.0125 & 0.0317 & 0.0057 & 0.0114 & 0.0526 \\
\hline & St. Desv. & 0.0274 & 0.0989 & 0.0039 & 0.0113 & 0.0027 & 0.0175 & 0.0028 & 0.0073 & 0.0384 \\
\hline \multirow{2}{*}{ 62. Permanent GAP (rel.) } & Mean & 0.0217 & 0.0000 & 0.6233 & 0.0000 & 0.0000 & 0.0010 & 0.0149 & 0.0047 & 0.0000 \\
\hline & St. Desv. & 0.0335 & 0.0000 & 0.2082 & 0.0000 & 0.0000 & 0.0021 & 0.0177 & 0.0066 & 0.0000 \\
\hline \multirow{2}{*}{$\begin{array}{l}\text { 67.PhysTremor Est. } \\
\text { Amplitude (\%) }\end{array}$} & Mean & 0.3407 & 3.26 & 0.1490 & 0.2245 & 0.0727 & 1.04 & 0.1742 & 0.0988 & 0.1300 \\
\hline & St. Desv. & 0.1697 & 5.13 & 0.0695 & 0.1258 & 0.0495 & 1.33 & 0.1436 & 0.0699 & 0.0654 \\
\hline \multirow{2}{*}{$\begin{array}{l}\text { 69. NeurTrem. Est. } \\
\text { Amplitude (\%) }\end{array}$} & Mean & 0.2830 & 2.82 & 0.1439 & 0.2090 & 0.0735 & 1.05 & 0.1691 & 0.0965 & 0.1201 \\
\hline & St. Desv. & 0.1552 & 4.79 & 0.0899 & 0.1140 & 0.0427 & 1.34 & 0.1427 & 0.0668 & 0.0683 \\
\hline \multirow{2}{*}{$\begin{array}{l}\text { 71. FlutTremor Est. } \\
\text { Amplitude (\%) }\end{array}$} & Mean & 0.2020 & 2.17 & 0.0867 & 0.1672 & 0.0601 & 0.8637 & 0.1406 & 0.0860 & 0.0874 \\
\hline & St. Desv. & 0.0940 & 3.65 & 0.0463 & 0.0989 & 0.0376 & 1.32 & 0.1143 & 0.0675 & 0.0495 \\
\hline \multirow{2}{*}{$\begin{array}{l}\text { 72. Global Tremor } \\
\text { (rMSA) (rel.) }\end{array}$} & Mean & 0.0050 & 0.0804 & 0.0023 & 0.0065 & 0.0022 & 0.0232 & 0.0049 & 0.0025 & 0.0035 \\
\hline & St. Desv. & 0.0027 & 0.1119 & 0.0012 & 0.0039 & 0.0012 & 0.0312 & 0.0040 & 0.0016 & 0.0016 \\
\hline
\end{tabular}

Table 5. Greyscale for above or below normality profile.

\begin{tabular}{|c|c|c|c|c|c|c|c|c|c|}
\hline Kolmogorov—Smirnov Z & SMS14 & SMS15 & SMS16 & SMS17 & SMS18 & SMS19 & SMS20 & SMS21 & SMS22 \\
\hline $\mathrm{N}$ & 5 & 5 & 5 & 5 & 5 & 5 & 5 & 5 & 5 \\
\hline 1. Absolute Pitch (Hz) & & & & & & & & & \\
\hline 2. Jitter (rel.) & & & & & & & & & \\
\hline 3. Shimmer (rel.) & & & & & & & & & \\
\hline 5. NHR (rel.) & & & & & & & & & \\
\hline 35. Body Mass (mg) & & & & & & & & & \\
\hline 37. Body Stiffness $(\mathrm{mN} / \mathrm{m})$ & & & & & & & & & \\
\hline 38. Body Mass Unbalance (rel.) & & & & & & & & & \\
\hline 40. Body Stiffness Unbalance (rel.) & & & & & & & & & \\
\hline 41. Cover Mass (mg) & & & & & & & & & \\
\hline 43. Cover Stiffness $(\mathrm{mN} / \mathrm{m})$ & & & & & & & & & \\
\hline 44. Cover Mass Unbalance (rel.) & & & & & & & & & \\
\hline 46. Cover Stiffness Unbalance (rel.) & & & & & & & & & \\
\hline 60. Contact gap (rel.) & & & & & & & & & \\
\hline 61. Adduction gap (rel.) & & & & & & & & & \\
\hline 62. Permanent gap (rel.) & & & & & & & & & \\
\hline 67. PhysTremor Est. Amplitude (\%) & & & & & & & & & \\
\hline 69. NeurTremor Est. Amplitude (\%) & & & & & & & & & \\
\hline 71. FlutTremor Est. Amplitude (\%) & & & & & & & & & \\
\hline 72. Global Tremor (rMSA) (rel.) & & & & & & & & & \\
\hline
\end{tabular}

\section{Discussion}

After detailed observation of the voice analysis results, several striking features have been found, which are discussed below.

Firstly, there does not seem to be a homogeneous profile. However, some features can be highlighted that may point to specific prominent characteristics of the phonation of the SMS. One of 
them could be the F0 that is noteworthy, being that 7 out of the 9 cases deviate from the normative reference. Specifically, these seven cases have a high F0, well above the adult normophonic profile, both female and male. This fact is even more remarkable if we take into account the data on weight and height of the cases studied. Some of the men with SMS have a height and weight above $1.70 \mathrm{~m}$ and $75 \mathrm{~kg}$, such as SMS17, SMS21, and SMS22, and have F0 values between 160 and $175 \mathrm{~Hz}$, which is a high fundamental frequency compared to the adult male voice. The opposite phenomenon is observed with SMS15, who is $1.55 \mathrm{~m}$ tall, weighs $50 \mathrm{~kg}$, and has an F0 of $114 \mathrm{~Hz}$. These findings would evidence the mismatch between the physical complexion and voice characteristics in the SMS population; although there is no clear consensus among researchers, it has been observed that the greater the size (especially in males), the lower the frequency range and formant profile (Rendall et al. 2005; Evans et al. 2006; Sataloff et al. 2007; Pisanski et al. 2014, 2016).

The results of the acoustic distortion parameters traditionally analyzed in voice acoustic studies (3. jitter, 4. shimmer and 5. NHR-noise/harmonic ratio) are surprising and unexpected. This is because only two cases have jitter values above the normative average and only four cases with SMS obtain shimmer and NHR results significantly far from the normality reference. These three acoustic parameters related to the degree of frequency and amplitude distortion and the degree of relative noise have traditionally been considered as indicators of dysphonia since anomalous results of jitter, shimmer, and NHR are detected in cases with vocal pathology. The perceived hoarseness and roughness in many voices in our sample led us to think that these three distortion parameters would give other results, different from the normative average.

The values of the vocal muscle stiffness feature (feature 37) are in relation to the finding of the high F0. It is important to note that all cases with an abnormal high F0 presented excessive vocal muscle stiffness at the same time. This feature 37 estimates the vocal muscle stiffness resulting from an excess of strain in phonation (Gómez-Vilda et al. 2007; Gómez et al. 2009, 2013a). This phenomenon could indicate a laryngeal hyperfunction in most of the cases studied. In this sense, feature 43 , related to the rigidity of the vocal fold cover, is striking since it does not reflect high values as those of feature 37 , but the opposite. Only three cases with SMS deviated from the normative average in feature 43, and two of them obtained values below it. This may suggest that the excess tension underlying the voice in our sample is due solely to vocal muscle stiffness.

Two other features are remarkable because of the results obtained in most of the participants with SMS: 35 and 41. These are related to the dynamic mass of the vocal muscle and the cover of the vocal fold, respectively (Table 2). In particular, the results of 35 and 41 could be related to the estimation of the dynamic mass of the muscle and the cover of the vocal fold (Gómez-Vilda et al. 2007; Gómez et al. 2009 , 2013a). In these two features, the results are significantly below the reference of normality, that is, it could be said that almost all cases with SMS have a dynamic mass of the vocal fold well below the adult average, both male and female. This phenomenon could be related to the maturity delay in people with SMS. Even this finding would lead us to hypothesize about the delay of voice change in adolescents with SMS. It would be very interesting to test in further investigations with a larger sample and from a longitudinal perspective if voice change occurs later or not in this population.

Concerning the airflow scape (features 60-62), feature 60 should be highlighted. This feature informs about the contact quality of the folds when the total closure of the vocal folds takes place and the degree of airflow scape. Only four cases out of nine have airflow leakage, as the results of feature 60 are significantly above the normative average. This finding could be explained by the excess vocal muscle stiffness of people with SMS, since an excessive stiffness and contracted vocal fold may not have the correct biomechanics, resulting in a leakage of airflow in the contact phase (Morrison and Rammage 1993). However, not all cases analyzed with excess stiffness present a contact defect. For this reason, this hypothesis should be tested in the future.

Finally, it is interesting to discuss the results of the features related to the presence of laryngeal tremor: from 67-72. There does not seem to be a homogeneous profile, as many cases are within the features of normality, and others, such as SMS16, SMS18, and SMS22, are not. Furthermore, if we only 
look at the global laryngeal tremor parameter (feature 72), we can see that six of the nine cases studied deviate from the normality reference with values under the normative adult voice. This phenomenon seems to be related to the values estimated in parameters 40 and 46 (Table 5) referring to body and cover stiffness unbalances, since most of the cases studied are within or below the normality profile. In previous studies with populations with neurological disorders, such as Parkinson's disease, it has been observed that estimates of laryngeal tremor (parameters 67-72) and those of body and cover stiffness unbalances (parameters 40 and 46) show a direct relationship (Gómez et al. 2016, 2017). In any case, the finding made in the present work related to the normal and low values of vocal tremor in individuals with SMS is unexpected and contrasts with the results obtained for the same parameters in those individuals with Williams syndrome, who obtained very high values of laryngeal tremor and vocal instability (Hidalgo et al. 2018). We could be looking at a phonatory peculiarity of adults with Smith-Magenis syndrome, although this hypothesis needs to be contrasted with a larger population. In any case, this seems to be a striking feature of the phonation of adults with SMS in this study.

It is worth mentioning that all these previous associations are not the result of a causal relationship between the phenomena characterized but are rather approaches to possible factors underlying the laryngeal biomechanics of adults with SMS described in this study.

In short, no homogeneous acoustic profile has been detected in the individuals enrolled in this study. However, all the cases analyzed differ from the normative reference in at least two features out of the 19 estimated for the analysis. This accounts for the existence of a phonatory profile different from the normative voices, indicating the presence of biomechanical peculiarities that could characterize the voice of people with SMS: a very high F0 related to age, sex and complexion, an excess of vocal muscle stiffness due to high laryngeal stress, and thinned vocal fold masses (of both the cover and the muscle).

\section{Conclusions}

The peculiar voice quality of Smith-Magenis syndrome and the previous study conducted in 2019 with children and adults with this syndrome motivated the implementation of this work on adult phonation only. In general, most of the studies carried out on the speech and voice characteristics of unknown syndromes are usually developed with child samples; this is one of the reasons we have focused on adult voices in SMS. In addition, we decided to examine only the adult voice because at this stage, some of the variables that directly influence phonation at earlier ages, which are related to adolescence and to voice change before age 15, have already stabilized-hormonal changes and physical development, among others (Hollien et al. 1994; Harries et al. 1997; Whiteside 2001; Whiteside et al. 2004). Finally, the main reason we decided to carry out this analysis is the apparent discordance between vocal timbre and complexion, age, and sex of individuals with SMS. This peculiar voice timbre could be related to some of the typical features of this syndrome, such as its severe behavioral problems, its anxious and hyperactive personality, its metabolic disorders, or its neuromotor problems (Elsea and Girirajan 2008; Smith et al. 2019). Previous studies carried out with groups with neurodegenerative disorders (such as Parkinson's or Alzheimer's type dementias) have shown that the voice is very susceptible to these neuropathic conditions (Chenausky et al. 2011; Tsanas 2012; Gómez et al. 2016, 2017, among others). It has also been proven that the clinical features of some syndromes that affect neurological development, such as Down syndrome or Williams syndrome, influence voice quality, specifically the condition and functioning of the vocal folds (Hidalgo et al. 2018; Hidalgo et al. forthcoming). For this reason, we considered it interesting to carry out an exploratory study on the phonation of adults with Smith-Magenis syndrome.

One of the first observations made after the study is that there seems to be no homogeneous phonatory profile. Another notable finding made is that there does not seem to be a correspondence between the voice pitch and the physical features of the patient, although the sample should be increased to be sure of these observations. The most relevant finding is that all the voices with SMS in this study present some particularities significantly different from the normative voice profile, such as an excess of body stiffness and a reduced dynamic mass of the vocal folds. These data are remarkable 
since there are studies published on SMS concerning behavioral, genetic, and sleep characteristics of this syndrome, but there is no study reporting that this population has a phonatory profile different from the pattern of normality in adulthood.

Finally, it is relevant to point out that the behavioral profile of the SMS could be conditioning the vocal phenotype: high F0 and excess stiffness of the vocal folds. The phonatory profiles found are individualized, but most of them show acoustic and biomechanical characteristics conditioned by their behavioral profile. It is necessary to enlarge the samples and, if possible, to add a non-normophonic population with typical development and population with behavioral problems similar to the SMS profile.

This study is limited by the size of the sample, which is quite common in studies focusing on rare diseases, since the prevalence is low and the number of diagnoses is small. In the case of SMS, there are only 73 patients diagnosed and registered at ASME in Spain, comprising all ages.

This study contributes to enriching the scarce knowledge that exists about SMS beyond the genetic, behavioral, and sleep disturbances that are the most representative and problematic aspects of the syndrome that have eclipsed research to the detriment of the study of aspects related to voice, speech, language, and communication. Knowledge of the nature of the voice timbre of the SMS population may be of interest to speech and voice therapy experts, professionals that most people affected by SMS turn to throughout their lives.

Author Contributions: I.H.-D.1.G.: data collection, analysis, and writing; E.G.-H.: data collection, analysis, and writing; P.G.-V.: analysis and writing. All authors have read and agreed to the published version of the manuscript.

Funding: This research was funded by grant TEC2016-77791-C4-4-R (Plan Nacional de I+D+i, Ministry of Economic Affairs and Competitiveness of Spain).

Acknowledgments: We would like to thank the families of people with SMS for allowing their children to participate in this study. We also acknowledge the support provided by the Spanish Association of Smith-Magenis (ASME) in contacting the families.

Conflicts of Interest: The authors declare no conflict of interest.

\section{References}

Agar, Georgi, Chris Oliver, Jayne Trickett, Lucy Licence, and Caroline Richards. 2020. Sleep disorders in children with Angelman and Smith-Magenis syndromes: The assessment of potential causes of disrupted settling and night time waking. Research in Developmental Disabilities 97: 1-11. [CrossRef]

Chenausky, Karen, Joel MacAuslan, and Richard Goldhor. 2011. Acoustic Analysis of PD Speech. Parkinson's Disease 2011: 435232. [CrossRef] [PubMed]

Di Cicco, Mauricio, Rita Padoanb, Giovanni Felisatia, D Dilanid, Eugenia Morettib, Silvana Guerneric, and Angelo Selicorni. 2001. Otorhinolaringologic manifestation of Smith-Magenis Syndrome. International Journal of Pediatric Otorhinolaryngology 59: 147-50. [CrossRef]

Dykens, Elisabeth, and Ann Smith. 1998. Distinctiveness and correlates of maladaptive behaviour in children and adolescents with Smith-Magenis syndrome. Journal of Intellectual Disability Research 42: 481-89. [CrossRef]

Dykens, Elisabeth, Brenda Finucane, and Claire Gayley. 1997. Brief report: Cognitive and behavioral profiles in persons with Smith-Magenis syndrome. Journal of Autism and Developmental Disorders 27: 203-11. [CrossRef] [PubMed]

Elsea, Sarah, and Santhosh Girirajan. 2008. Smith-Magenis syndrome. European Journal of Human Genetics 16: 412-21. [CrossRef]

Evans, Sarah, Nick Neave, and Delia Wakelin. 2006. Relationships between vocal characteristics and body size and shape in human males: An evolutionary explanation for a deep male voice. Biological Psychology 72: 160-63. [CrossRef]

Fant, Gunnar, Johan Liljencrants, and Qi-guang Lin. 1985. A four-parameter model of glottal flow. STL-QPSR 4: $1-13$.

Garayzábal, Elena, Ana Osório, María Lens, and Adriana Sampaio. 2014. Concrete and relational vocabulary: Comparison between Williams and Smith-Magenis syndromes. Research in Developmental Disabilities 35: 3365-71. [CrossRef] 
Garayzábal Heinze, Elena, María Lens Villaverde, Tatitana Conde, Luis Felipe Moura, Montserrat Fernández, and Adriana Sampaio. 2011. Funcionamiento cognitivo general y habilidades psicolingüísticas en niños con síndrome de Smith-Magenis. Psicothema 23: 725-31.

Gómez, Pedro, Roberto Fernández, Victoria Rodellar, Víctor Nieto, Agustín Álvarez, Luis Mazaira, Rafael Martínez, and Juan Ignacio Godino. 2009. Glottal Source Biometrical Signature for Voice Pathology Detection. Speech Communication 51: 759-81. [CrossRef]

Gómez, Pedro, Victoria Rodellar, Víctor Nieto, Cristina Muñoz, Luis Mazaira, Carlos Ramírez, Mario Fernández, and Elvira Toribio. 2011. Neurological Disease Detection and Monitoring from Voice Production. In Advances in Nonlinear Speech Processing. NOLISP 2011. Lecture Notes in Computer Science. Edited by Carlos M. Travieso-González and Jesús Alonso-Hernández. Berlin/Heidelberg: Springer, vol. 7015, pp. 1-8. [CrossRef]

Gómez, Pedro, Victoria Rodellar, Víctor Nieto, Rafael Martínez, Agustín Álvarez, Bartolomé Scola, Carlos Ramírez, Daniel Poletti, and Mario Fernández. 2013a. BioMetPhon: A System to Monitor Phonation Quality in the Clinics. Paper presented at the 5th International Conference on e-Health, Telemedicione and Social Medicine, Nice, France, 24 February-1 March 2013. Edited by Julia van Gemert-Pijnen and Hans Ossebaard. Red Hook: Curran Associates Inc., pp. 253-58.

Gómez, Pedro, Víctor Nieto, Victoria Rodellar, Agustín Álvarez, Luis mazaira, Rafael Martínez, Cristina Muñoz, Mario Fernández, and Carlos Ramírez. 2013b. Estimating Tremor in Vocal Fold Biomechanics for Neurological Disease Characterization. Paper presented at the 18th International Conference on Digital Signal Processing (DSP) 2013, Santorini, Greece, 1-3 July 2013. Piscataway: IEEE. Available online: http://ieeexplore.ieee.org/ servlet/opac?punumber $=6599036$ (accessed on 27 April 2020).

Gómez, Pedro, Agustín Álvarez-Marquina, Athnasios Tsanas, Carlos Alfredo Lázaro-Carrascosa, Victoria Rodellar-Biarge, Víctor Nieto-Lluis, and Rafael Martínez-Olalla. 2016. Phonation Biomechanics in Quantifying Parkinson's Disease Symptom Severity. In Recent Advances in Nonlinear Speech Processing. Edited by Anna Esposito, Marcos Faundez-Zanuy, Antonietta M. Esposito, Gennaro Cordasco, Thomas Drugman, Jordi Solé-Casals and Francesco Carlo Morabito. Cham: Springer International Publishing, pp. 93-112.

Gómez, Pedro, Daniel Palacios-Alonso, Victoria Rodellar-Biarge, Agustín Álvarez-Marquina, Víctor Nieto-Lluis, and Rafael Martínez-Olalla. 2017. Parkinson's disease monitoring by biomechanical instability of phonation. Neurocomputing 255: 3-16. [CrossRef]

Gómez-Vilda, Pedro, Roberto Fernández-Baillo, Alberto Nieto, Francisco Diaz, Francisco J. Fernández-Camacho, Victoria Rodellar, Agustín Álvarez, and Rafael Martınez. 2007. Evaluation of Voice Pathology Based on the Estimation of Vocal Fold Biomechanical Parameters. Journal of Voice 21: 450-76. [CrossRef] [PubMed]

Greenberg, Frank, Richard Lewis, Lorraine Potocki, Daniel Glaze, Julie Parke, James Killian, Mary Ada Murphy, Daniel Williamson, Frank Brown, Robert Dutton, and et al. 1996. Multi-disciplinary clinical study of Smith-Magenis syndrome (deletion 17p11. 2). American Journal of Medical Genetics 62: 247-54. [CrossRef]

Gropman, Andrea, Ann Smith, JE Allanson, and Frank Greenberg. 1998. Smith Magenis syndrome: Aspects of the infant phenotype. The American Journal of Human Genetics 63: A19.

Gropman, Andrea, Wallace Duncan, and Ann Smith. 2006. Neurologic and developmental features of the Smith-Magenis syndrome (del 17p11.2). Pediatric Neurology 34: 337-50. [CrossRef]

Harel, Brian, Michael Cannizzaro, Henrí Cohen, Nicole Reilly, and Peter Snyder. 2004. Acoustic characteristics of Parkinsonian speech: A potential biomarker of early disease progression and treatment. Journal of Neurolinguistics 17: 439-53. [CrossRef]

Harries, Meredydd, John Walker, D. M. Williams, Sara Hawkins, and Ieuan Hughes. 1997. Changes in the male voice at puberty. Archives of Disease in Childhood 77: 445-47. [CrossRef]

Heinze, Elena Garayzábal, and María Lens. 2013. Guía de Intervención Logopédica: El Síndrome de Smith-Magenis. Madrid: Síntesis.

Hidalgo de la Guía, Irene. 2019. El Nivel Fónico de la Población con Síndrome de Smith Magenis: Particularidades Fonatorias y Fonético-Fonológicas. Comparativa con Síndrome de Williams, Síndrome de Down y Desarrollo Típico. Ph.D. dissertation, Universidad Autónoma de Madrid, Madrid, Spain.

Hidalgo, Irene, and Elena Garayzábal. 2019. Diferencias fonológicas entre síndromes del neurodesarrollo: Evidencias a partir de los procesos de simplificación fonológica más frecuentes. Revista de Invetigación en Logopedia 9: 81-106. [CrossRef] 
Hidalgo, Irene, Pedro Gómez, and Elena Garayzábal. 2018. Biomechanical Description of Phonation in Children Affected by Williams Syndrome. Journal of Voice 32: 515.e15-515.e28. [CrossRef]

Hidalgo, Irene, Elena Garayzábal, Pedro Gómez-Vilda, and Daniel Pacios-Alonso. Forthcoming. Specificities of Phonation Biomechanics in Down Syndrome Children. Biomedical Signal Processing and Control.

Hollien, Harry, Rachel Green, and Karen Massey. 1994. Longitudinal research on adolescent voice change in males. The Journal of the Acoustical Society of America 96: 2646-54. [CrossRef] [PubMed]

Martin, Stacy, Pamela Wolters, and Ann Smith. 2006. Adaptive and maladaptive behavior in children with Smith-Magenis Syndrome. Journal of Autism and Developmental Disorders 36: 541-52. [CrossRef]

Morrison, Murray D., and Linda A. Rammage. 1993. Muscle misuse voice disorders: Description and classification. Acta oto-laryngologica 113: 428-34. [CrossRef] [PubMed]

Nag, Heidi, and Terje Nærland. 2020. Age-related changes in behavioural and emotional problems in Smith-Magenis syndrome measured with the Developmental Behavior Checklist. Journal of Intellectual Disabilities. [CrossRef]

Osório, Ana, Raquel Cruz, Adriana Sampaio, Elena Garayzábal, Ángel Carracedo, and Montserrat Férnandez Prieto. 2012. Cognitive functioning in children and adults with Smith-Magenis Syndrome. European Journal of Medical Genetics 55: 394-99. [CrossRef]

Pisanski, Katarzyna, Paul J. Fraccaro, Cara C. Tigue, Jillian J. O'Connor, Susanne Röder, Paul W. Andrews, Bernahrd Fink, Lise DeBruine, Benedict Jones, and David R. Feinberg. 2014. Vocal indicators of body size in men and women: A meta-analysis. Animal Behaviour 95: 89-99. [CrossRef]

Pisanski, Katarzyna, Benedict C. Jones, Bernhard Fink, Jillian J. O’Connor, Lise M. DeBruine, Susanne Röder, and David R. Feinberg. 2016. Voice parameters predict sex-specific body morphology in men and women. Animal Behaviour 112: 13-22. [CrossRef]

Rendall, Drew, Sophie Kollias, Christine Ney, and Peter Lloyd. 2005. Pitch (F0) and formant profiles of human vowels and vowel-like baboon grunts: The role of vocalizer body size and voice-acoustic allometry. The Journal of the Acoustical Society of America 117: 944-55. [CrossRef]

Sarimski, Klaus. 2004. Communicative competence and behavioural phenotype in children with Smith-Magenis syndrome. Genetic Counselling 15: 347-55.

Sataloff, Robert. T., Yola D. Heman-Ackah, and Mary J. Hawkshaw. 2007. Clinical anatomy and physiology of the voice. Otolaryngologic clinics of north America 40: 909-29. [CrossRef]

Shayota, Brian, and Sarah Elsea. 2019. Behavior and sleep disturbance in Smith-Magenis syndrome. Current Opinion in Psychiatry 32: 73-78. [CrossRef]

Smith, Ann, Loris McGavran, and Gail Waldstein. 1982. Deletion of the 17 short arm in two patients with facial clefts. American Journal of Human Genetics 34: A410.

Smith, Ann C. M., Rebecca S. Morse, Wendy Introne, and Wallace C. Duncan Jr. 2019. Twenty-four-hour motor activity and body temperature patterns suggest altered central circadian timekeeping in Smith-Magenis syndrome, a neurodevelopmental disorder. American Journal of Medical Genetics Part A 179: 224-36. [CrossRef] [PubMed]

Solomon, Beth, Linda McCullah, D. Krasenwich, and Ann Smith. 2002. Oral sensory motor, swallowing and speech findings in Smith Magenis syndrome: A research update. American Society of Human Genetic Research 71: 271.

Tsanas, Athanasios. 2012. Accurate Telemonitoring of Parkinson's Disease Symptom Severity Using Nonlinear Speech Signal Processing and Statistical Machine Learning. Ph.D. thesis, Oxford University, Oxford, UK.

Udwin, Orlee, Carolyn Webber, and Isobele Horn. 2001. Abilities and attainment in Smith-Magenis syndrome. Development Medicine and Child Neurology 43: 823-28. [CrossRef] [PubMed]

Webber, Carolyn. 1999. Cognitive and Behavioural Phenotype of Children with Smith-Magenis Syndrome. Ph.D. thesis, University of Leicester, Leicester, UK.

Whiteside, Sandra. 2001. Sex-specific fundamental and formant frequency patterns in a cross-sectional study. The Journal of the Acoustical Society of America 110: 464-78. [CrossRef] [PubMed]

Whiteside, Sandra, Luisa Henry, and Rachel Dobbin. 2004. Sex differences in voice onset time: A developmental study of phonetic context effects in British English. The Journal of the Acoustical Society of America 116: 1179-83. [CrossRef]

Wilde, Lucy, Daniel Silva, and Chris Oliver. 2013. The nature of social preference and interactions in Smith-Magenis syndrome. Research in Developmental Disabilities 34: 4355-65. [CrossRef] 
Wolters, Pamela, Andrea Gropman, Staci Martin, Michaele Smith, Hanna Hildenbr, Carmen Brewer, and Ann Smith. 2009. Neurodevelopment of children under 3 years of age with Smith-Magenis syndrome. Pediatric Neurology 41: 250-58. [CrossRef]

Yunusova, Yana, Gary Weismer, John Westbury, and Mary Lindstrom. 2008. Articulatory movements during vowels in speakers with dysarthria and healthy controls. Journal of Speech, Language, and Hearing Research 51: 596-611. [CrossRef] article distributed under the terms and conditions of the Creative Commons Attribution (CC BY) license (http://creativecommons.org/licenses/by/4.0/). 